\title{
An Immunosensor for Pathogenic Staphylococcus aureus Based on Antibody Modified Aminophenyl-Au Electrode
}

\author{
Amani Chrouda, ${ }^{1,2}$ Mohamed Braiek, ${ }^{1}$ Karima Bekir Rokbani, ${ }^{3}$ Amina Bakhrouf, ${ }^{3}$ \\ Abderrazak Maaref, ${ }^{2}$ and Nicole Jaffrezic-Renault ${ }^{1}$ \\ ${ }^{1}$ Institute of Analytical Sciences, University of Lyon, UMR CNRS 5280, 5 rue de la Doua, 69100 Villeurbanne, France \\ ${ }^{2}$ Laboratory of Interfaces and Advanced Materials, Faculty of Sciences, University of Monastir, Avenue de l'Environnement, \\ 5019 Monastir, Tunisia \\ ${ }^{3}$ Laboratory of Analysis, Treatment and Valorisation of Pollutants of Environment and of Products, Faculty of Pharmacy, \\ University of Monastir, 5019 Monastir, Tunisia
}

Correspondence should be addressed to Nicole Jaffrezic-Renault; nicole.jaffrezic@univ-lyonl.fr

Received 8 August 2013; Accepted 9 September 2013

Academic Editors: S. Arya and E. M. Richter

Copyright (C) 2013 Amani Chrouda et al. This is an open access article distributed under the Creative Commons Attribution License, which permits unrestricted use, distribution, and reproduction in any medium, provided the original work is properly cited.

The objective of this work is to elaborate an immunosensing system which will detect and quantify Staphylococcus aureus bacteria. A gold electrode was modified by electrografting of 4-nitrophenyl diazonium, in situ synthesized in acidic aqueous solution. The immunosensor was fabricated by immobilizing affinity-purified polyclonal anti S. aureus antibodies on the modified gold electrode. Cyclic voltammetry (CV) and Faradaic Electrochemical Impedance Spectroscopy (EIS) were employed to characterize the stepwise assembly of the immunosensor. The performance of the developed immunosensor was evaluated by monitoring the electron-transfer resistance detected using Faradaic EIS. The experimental results indicated a linear relationship between the relative variation of the electron transfer resistance and the logarithmic value of $S$. aureus concentration, with a slope of $0.40 \pm 0.08$ per decade of concentration. A low quantification limit of $10 \pm 2 \mathrm{CFU}$ per $\mathrm{ml}$ and a linear range up to $10^{7} \pm 2 \times 10^{6} \mathrm{CFU}$ per $\mathrm{mL}$ were obtained. The developed immunosensors showed high selectivity to Escherichia coli and Staphylococcus saprophyticus.

\section{Introduction}

Staphylococcus aureus is a major human pathogen responsible for a broad range of diseases because it is able to produce heat-resistant toxins in food [1]. Foods that are frequently incriminated in staphylococcal poisoning include meat and meat products, milk, and water. The toxic chemical released by $S$. aureus is enterotoxin that has been found to be produced at a hazardous level for $10^{8}$ cells per $\mathrm{kg}$ of food [2]. Therefore rapid, sensitive, and reliable methods to detect foodborne pathogens are increasingly necessary in health care today. Traditional methods for foodborne bacteria detection including polymerase chain reaction (PCR) [3], enzyme-linked immunosorbent assay [4], and those based on culture and colony counting [5] have been widely applied due to their high reliability. However, these methods suffer from obvious disadvantages: they are time consuming and require expensive equipment and complicated pretreatment, so they are difficult to use on site.

Biosensor technologies play an increasingly important role in the detection of pathogenic bacteria because they present the great potential of satisfying the practical need for rapid, wearable, and low-cost detection [6]. Among biosensors, immunosensors are widely investigated for bacteria detection due to their specific advantages, such as high affinity and simple fabrication $[6,7]$. In the literature, many recent studies focus on E. coli and Salmonella bacteria detection with different transducing techniques: QCM [8], SPR [9], electrochemical techniques: capacitive [10] and amperometric measurements [11]. Although several electrochemical immunosensors for the detection of foodborne pathogenic bacteria have been reported in the literature, 
only a few of them have been used for the quantification of $S$. aureus [12-14]. Escamilla-Gómez et al. reported an amperometric immunosensor for the determination of $S$. aureus cells, obtaining a detection limit of $3.7 \times 10^{2}$ cells per $\mathrm{mL}$ [12]. Tan et al. have developed a PDMS-based microfluidic immunosensor chip for the detection of foodborne pathogens $S$. aureus and E. coli O157: the detection limit of this impedimetric immunosensor modified with a nanoporous alumina membrane was around $10^{2} \mathrm{CFU}$ per $\mathrm{mL}$ [13]. Braiek et al. [14] have used a self-assembled monolayer of alkanethiols for the antibody immobilization on gold surface and EIS for the immunodetection of $S$. aureus and have reported a sensor sensitivity of $127 \Omega$ per decade of CFU with a detection limit of $10 \mathrm{CFU}$ per $\mathrm{mL}$ [14].

The originality reported in this present study is the development of an immunosensor based on a diazonium electrografted gold electrode for the detection of $S$. aureus, which has never been tested until now. The method for elaborating stable thin organic layers on conductive substrates such as glassy carbon (GC), carbon nanotubes, HOPG, gold, metals, and on semiconductive substrates is now recognized as being an efficient procedure [15-22]. The mechanism by which aryl groups attach themselves to gold is not fully understood, although there is a good evidence for the formation of $\mathrm{Au}-\mathrm{C}$ bonds [23] which, in the case of aryldiazonium, results in quite a stable layer. By comparison, alkanethiol layers, that are highly stable [24], can only be applied to a rather limited number of materials $(\mathrm{Au}, \mathrm{Ag}, \ldots)$, whereas aryldiazonium layers can also be applied to carbonaceous materials. The use of electroreduction of aryl diazonium salts provides higher stability with respect to long-term storage in air, potential use in cyclic voltammetry under acidic conditions, and a wider potential window for subsequent electrochemistry [25]. Diazonium salt molecules, modified with various functional groups, have been used for the immobilization of nanoparticles [26], DNA [27], enzymes [28], carbon nanotubes $[29,30]$, proteins, antibodies and electroactive species [31-34] on GC, $\mathrm{Si}$, and Au surfaces. Moreover, applying an electrochemical potential to the specific electrode (chip) allows biomolecule immobilization which should be compatible with the production of biochip microarrays for multidetection.

In this work, anti-S. aureus antibody is covalently anchored onto a gold electrode surface through grafting onto p-aminophenyl groups, in situ generated in the aqueous deposition solution. The aryl diazonium covalently binds to the surface by the spontaneous release of nitrogen [35, 36], and the nitro group is then reduced. The different steps for immunosensor elaboration have been characterized using electrochemical measurements. The EIS technique is an efficient electrochemical technique for the transduction of biosensing events on electrodes [37, 38], and is therefore used here for affinity assays: antibody-cell binding. By modeling Nyquist plots, a calibration curve for $S$. aureus has been determined, and the analytical characteristics of this immunosensor have been deduced and compared to those of previous relevant immunosensors.

\section{Experimental}

2.1. Reagents. Polyclonal antibodies (developed in rabbit) against Staphylococcus aureus were obtained from BIOtech RDP (Sfax, Tunisia). P-nitroaniline (PNA), hydrochloric acid (37\%), sodium nitrite, phosphate buffered saline (PBS), potassium ferrocyanide $\left[\mathrm{K}_{4} \mathrm{Fe}(\mathrm{CN})_{6}\right]$, potassium ferricyanide $\left[\mathrm{K}_{3} \mathrm{Fe}(\mathrm{CN})_{6}\right]$, hydrogen peroxide (30\%), glutaraldehyde $(25 \%)$, and bovine serum albumin (BSA) were purchased from Sigma Aldrich. All solutions were prepared with ultra-pure Milli-Q water.

2.2. Bacteria Cultivation. S. aureus reference strain (ATCC25923) was used in the present study. The bacteria strain was cultured in a tryptic soy broth [TSB, (Difco)] or on TSB agar plates for $24 \mathrm{hrs}$ at $37^{\circ} \mathrm{C}$. A highly concentrated bacteria suspension was prepared as follows: the liquid culture medium was inoculated with $100 \mu \mathrm{L}$ of pre-culture solution and then cultivated at $37^{\circ} \mathrm{C}$ for $18-24 \mathrm{hrs}$. The bacterial culture was centrifuged for $5 \mathrm{~min}$ at $6400 \mathrm{rpm}$ and then washed twice. Finally, it was resuspended in sterile phosphate-buffered saline (PBS). The proportions of viable cells and bacterial concentration were determined by the spread-plate technique. Optical density (OD), measured using a spectrophotometer, was used as a measure of the concentration of bacteria in a suspension. The cultures of $S$. aureus strain were grown to the stationary growth phase for $\mathrm{OD}_{600}=0.6$. At the stationary growth phase, bacterial concentration did not change with time, and, subsequently, all the operations to determine bacterial concentration can be performed accurately [14].

2.3. Electrochemical Instrumentation. Electrochemical measurements were performed using a Voltalab 40 potentiostatgalvanostat with a standard three-electrode configuration. The measurement set-up consisted of a three-electrode system, with a gold electrode (surface area $A=0.07 \mathrm{~cm}^{2}$ ) as the working electrode, a saturated calomel electrode (SCE) as the reference electrode and a platinum plate as the counter electrode.

All electrochemical measurements were carried out in a measuring chamber of volume $V$ (chamber) $=5 \mathrm{~mL}$ and inside a Faraday cage, at room temperature $T=$ $296( \pm 3) K\left(23 \pm 3^{\circ} \mathrm{C}\right)$.

Two-electrochemical techniques were used in this work as follows.

(i) Cyclic voltammetry was performed in $5 \mathrm{mM}$ ferro/ ferricyanide PBS solution $(8 \mathrm{mM})$ at a scan rate of $100 \mathrm{mV} / \mathrm{s}$.

(ii) Faradaic EIS was used by applying a small sinusoidal signal (amplitude $10 \mathrm{mV}$; frequency range $100 \mathrm{mHz}$ to $100 \mathrm{kHz}$ ) to the system at open circuit potential in $5 \mathrm{mM}$ ferro/ferricyanide PBS solution (8 $\mathrm{mM})$.

(iii) The $Z_{\text {view }} / Z_{\text {plot }}$ modeling software compatible with Windows (provided by Scribner Associate Inc, Southern Pines, NC, USA) was used for fitting the Faradaic impedance spectra. 


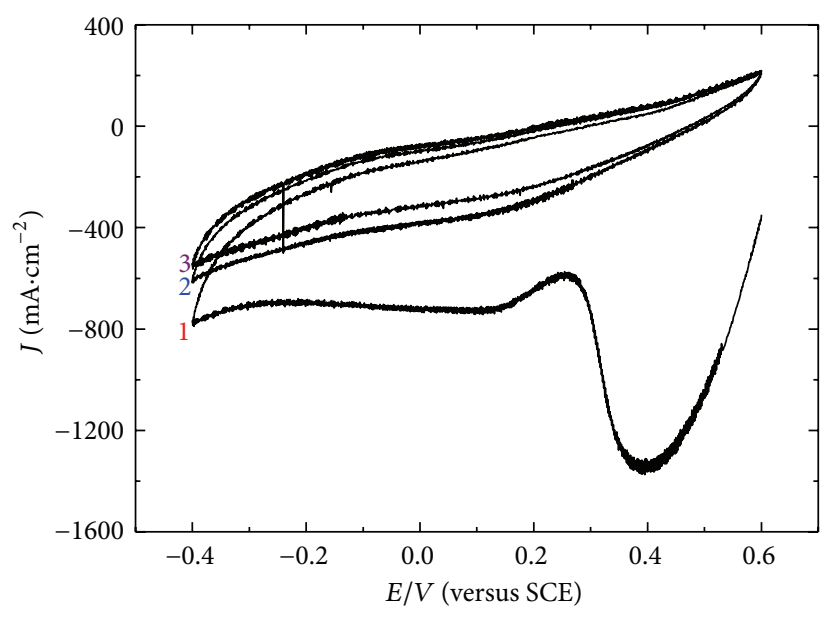

(a)

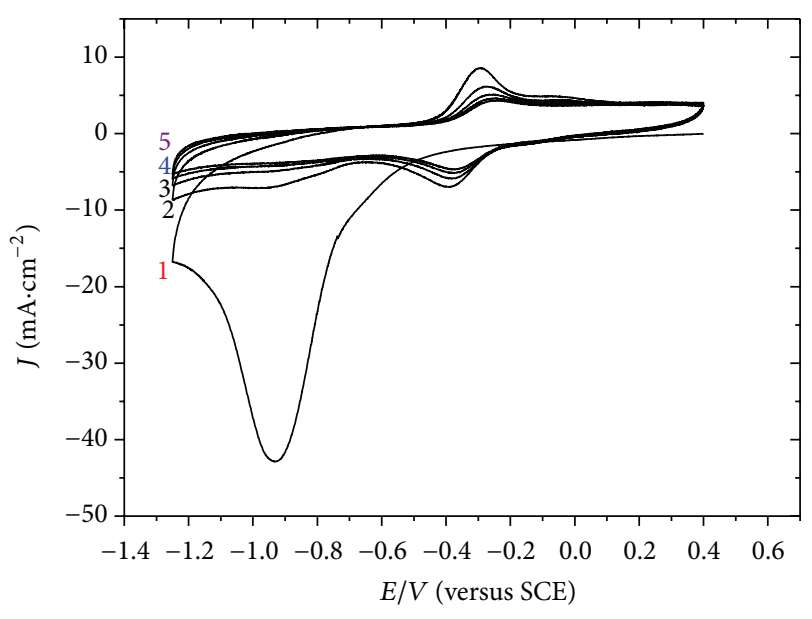

(b)

FIGURE 1: (a) Three cyclic voltammograms (numbered) for in situ-generated p-nitrophenyl diazonium salt (p-NP) at gold electrode in acidic solution, $\mathrm{HCl}(0.5 \mathrm{M})$, scan rate $100 \mathrm{mV} / \mathrm{s}$. (b) Five successive cyclic voltammograms (numbered) of p-nitrophenyl-modified gold electrode in $0.1 \mathrm{M} \mathrm{KCl}$; scan rate $100 \mathrm{mV} / \mathrm{s}$.

\section{Results and Discussion}

\subsection{Functionalization of the Electrode Surface with p-Nitrophenyldiazonium Cation}

3.1.1. Formation of p-Nitrophenyl Diazonium Cation. The gold surface was cleaned in acetone, in an ultrasonic bath for $10 \mathrm{~min}$, dried under a nitrogen flow, and then dipped for 2 min into a piranha solution $4: 1(\mathrm{v} / \mathrm{v})$ [98\% $\mathrm{H}_{2} \mathrm{SO}_{4} / 30 \%$ $\mathrm{H}_{2} \mathrm{O}_{2}$ ], rinsed with ultrapure water and dried under a nitrogen flow. The diazonium cations were synthesized in situ in accordance according to previously described procedure [35]: $20 \mathrm{mM}$ of $\mathrm{NaNO}_{2}$ was added to the electrolytic solution containing $20 \mathrm{mM}$ p-nitroaniline (PNA) in $0.5 \mathrm{M} \mathrm{HCl}$ under stirring at room temperature. The solution was cooled in an ice bath (the temperature did not exceed $0^{\circ} \mathrm{C}$ ).

3.1.2. Grafting of p-Nitrophenyl Diazonium Salt. The electrochemical grafting on golf electrode was immediately performed in the mixture above described, by cyclic voltammetry (three cycles from 0.6 to $-0.4 \mathrm{~V} / \mathrm{SCE}$ at a scan rate of $100 \mathrm{mV} / \mathrm{s}$ ). The consecutive cyclic voltammograms (CVs) of p-nitrophenyl diazonium at the gold electrode are presented in Figure 1(a).

The CVs are characterized by the first cycle exhibiting a well-defined, reproducible, and irreversible reduction peak located at $0.4 \mathrm{~V} / \mathrm{SCE}$. This feature corresponds to the typical electro-reduction reaction of the diazonium function, leading to the elimination of a nitrogen molecule and the production of highly reactive radicals. This radical was previously shown to attack the surface and to form a covalent bond between the aryl group and the Au electrode [39, 40].

Very low currents were observed during the second and third voltammetric cycles, evidencing that surface saturation of grafted molecules has been achieved. Although Brooksby and Downard have pointed out that the electrochemical determination of surface concentration must be interpreted with caution $[41,42]$, they assume a surface concentration of $\mathrm{nmol} / \mathrm{cm}^{2}$ for one monolayer [43].

The surface concentration, $\Gamma_{\mathrm{NP}}$, of the grafted nitrophenyl (NP) groups can be calculated according to the following formula:

$$
\Gamma_{\mathrm{NP}}=\frac{Q}{n F A}
$$

$Q(C)$ is the charge corresponding to the integral $J(t) d t$, which is the area of the current time reduction peak located at 0.4 V/SCE (cf Figure 1(a)). It was calculated using Origin 8 software. $n$ is the number of electrons exchanged per reactant molecule $(n=1), F$ is the Faraday constant $(96.500 \mathrm{C} / \mathrm{mol})$ and $A$ is the surface area of the working electrode.

A surface concentration (mole coverage) of $\mathrm{p}$-NP: $\mathrm{G}(\mathrm{NP})=3.4( \pm 0.3) \mathrm{nmol} / \mathrm{cm}^{2}$ was found, when the experiments were repeated three times in the same conditions. The surface concentration of $\mathrm{p}-\mathrm{NP}$ on the Au surface is then found as a significantly higher coverage than one monolayer for the first voltammetric half cycle.

3.1.3. Reduction of Nitrophenyl Group to Aminophenyl Group. The electrode was then washed and transferred to $0.1 \mathrm{M}$ $\mathrm{KCl}$ solution and subjected to five potential scans between 0.4 and $-1.25 \mathrm{~V} / \mathrm{SCE}$ at $100 \mathrm{mV} / \mathrm{s}$ in order to reduce the nitro group and obtain a modified film of 4-aminophenyl on the electrode surface. Figure 1(b) shows a cathodic sweep of the p-nitrophenyl modified gold electrode with an irreversible reduction peak at around $-0.9 \mathrm{~V} / \mathrm{SCE}$. During the second scan, the reduction peak is drastically diminished, indicating that nearly all the electroactive $-\mathrm{Ph}-\mathrm{NO}_{2}$ groups are reduced in the first scan. However, as pointed out in previous works [15-17], the reduction of $-\mathrm{Ph}-\mathrm{NO}_{2}$ to $-\mathrm{Ph}-$ $\mathrm{NH}_{2}$ is incomplete as evidenced by the reversible couple that appears at $E_{1 / 2}=-0.26 \mathrm{~V} / \mathrm{SCE}$. This couple is assigned to the hydroxyaminophenyl/nitroso phenyl interconversion. 


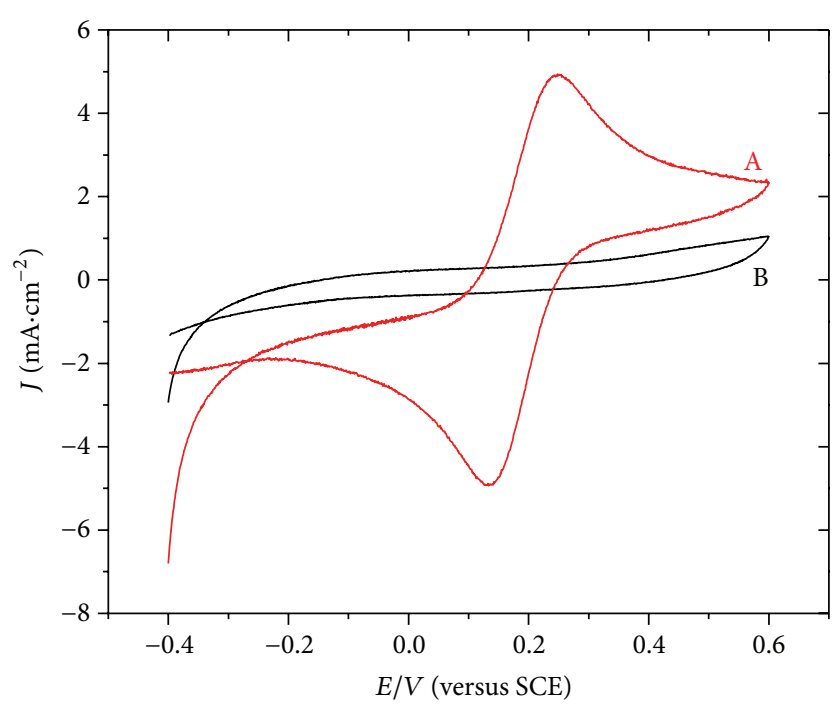

(a)

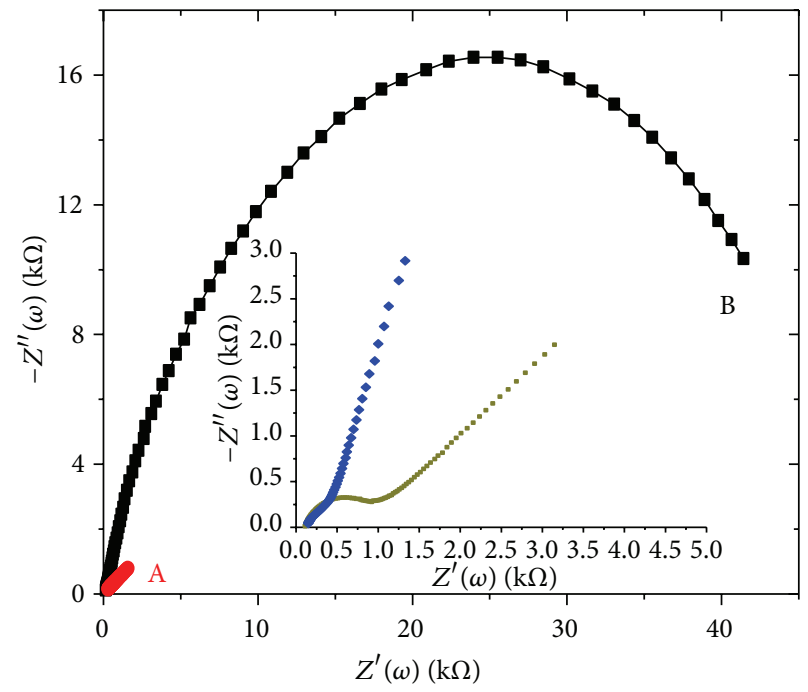

(b)

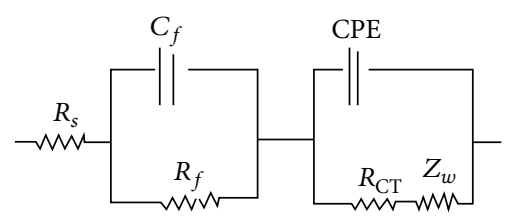

(c)

Figure 2: (a) Cyclic voltammograms of $5 \mathrm{mM} \mathrm{Fe}(\mathrm{CN})_{6}{ }^{3-/ 4-}$ at scan rate of $100 \mathrm{mV} / \mathrm{s}$ (A) on bare electrode, (B) on p-AP-Au electrode. (b) Nyquist plots in $5 \mathrm{mM} \mathrm{Fe}(\mathrm{CN})_{6}^{3-/ 4-}$ at open circuit potential using frequency range of $10 \mathrm{kHz}$ to $10 \mathrm{mHz}(\mathrm{A})$ on bare electrode, (B) on p-AP$\mathrm{Au}$ electrode. (c) An electrical equivalent circuit for both a bare and a modified electrode which comprises a series resistance $R_{S}$ (resistance of solution and of ohmic contacts), an interfacial film resistance $R_{f}$, an interfacial film capacity $C_{f}$, a resistance related to the charge transfer rate of redox reactions at the functionalized electrode $R_{\mathrm{CT}}$, a constant phase element (CPE) related to the capacitance of the functionalized Au electrode/electrolyte interface.

Once the p-aminophenyl layer had been formed, the electrochemical behavior of the modified gold electrode surface was investigated by cyclic voltammetry in the presence of the $\mathrm{Fe}^{2+} / \mathrm{Fe}^{3+}$ redox couple. Figure 2(a) shows the cyclic voltammogram for bare Au electrode and for aminophenylAu electrode, in the presence of the $\mathrm{Fe}^{2+} / \mathrm{Fe}^{3+}$ redox couple. This voltammogram is highly affected by the deposited layer; the redox peaks have entirely disappeared as expected for completely blocked surfaces. The aminophenyl (pAP) group is assumed to be covalently grafted to the Au surface through the formation of an $\mathrm{Au}-\mathrm{C}$ bond $[43,44]$. From the literature, after diazonium cation reduction, the stability of a diazonium compound on gold electrodes is weaker than on glassy carbon electrodes [45].

Electrochemical impedance spectroscopy measurements were also performed to further characterize the modified surfaces. Impedance $Z(\omega)$ is a complex number, according to (2)

$$
Z(\omega)=Z^{\prime}(\omega)+j \cdot Z^{\prime \prime}(\omega),
$$

where $\omega$ is the angular frequency, $j=\sqrt{-1}$ is the imaginary number and $\omega$, the angular frequency is equal to $2 \pi f, f$ being ac-frequency.
Impedance $Z(\omega)$ is represented in the complex plane, according to a Nyquist plot: imaginary part $\left(-Z^{\prime \prime}(\omega)\right)$ versus Real part $\left(Z^{\prime}(\omega)\right)$. Figure 2(b) represents the Nyquist plots for bare Au electrode and for aminophenyl-Au electrode. Indeed, the charge-transfer resistance, estimated from the diameter of the semi-circle of the Nyquist plot, is higher for the p-AP-Au electrode than for the bare gold electrode. This is due to the lower rate of electron transfer through the film, showing high coverage at the electrode.

An electrical equivalent circuit for both a bare and a modified electrode, shown in Figure 2(c), comprises a series resistance $R_{S}$ (resistance of solution and of ohmic contacts), a resistance related to the charge transfer rate of redox reactions at the functionalized electrode $R_{\mathrm{CT}}$, a constant phase element (CPE) related to the capacitance of the functionalized $\mathrm{Au}$ electrode/electrolyte interface. The capacitance of the interfacial film $C_{f}$ in parallel with the resistance of the interfacial film $R_{f}$ are also included in the equivalent circuit.

It is worth noting that the CPE reflects the nonideality of the double-layer at the functionalized gold electrode/electrolyte interface due to the roughness and porosity of the interfacial film. 


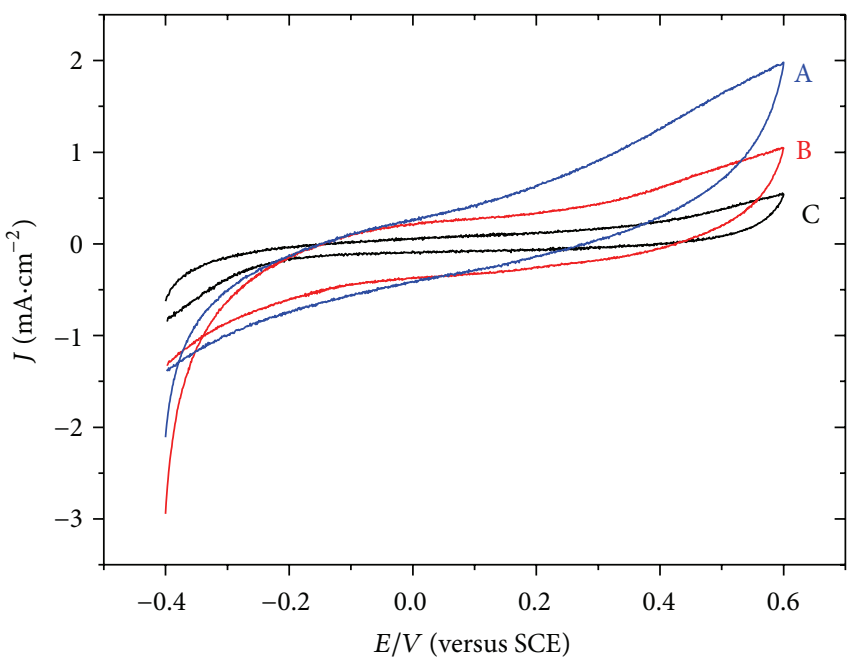

(a)

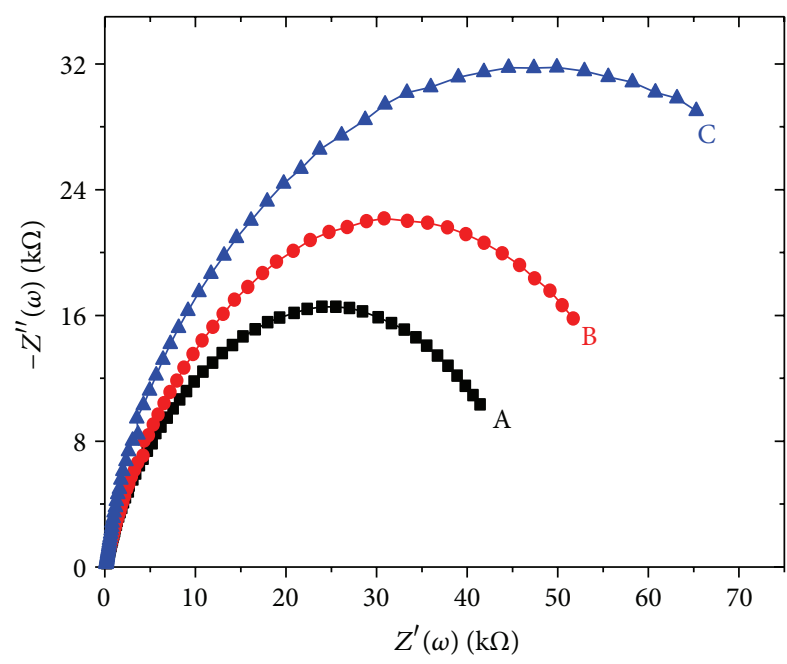

(b)

Figure 3: (a) Cyclic voltammograms of (A) p-AP-Au electrode, (B) p-AP+GA-Au electrode, and (C) antibody modified Au-p-AP+GA-Au electrode, recorded in the presence of $\mathrm{Fe}\left(\mathrm{CN}_{6}\right)^{3-} /^{4-}$ as a redox probe at scan rate of $100 \mathrm{mV} / \mathrm{s}$. (b) Nyquist plots of impedance spectra of $(\mathrm{A})$ Au-p-AP, (B) with Au-p-AP+GA, and (C) with antibody modified Au-p-AP+GA, recorded in the presence of Fe $\left(\mathrm{CN}_{6}\right)^{3-} /{ }^{4-}$ at a frequency range between $0.1 \mathrm{~Hz}$ and $100 \mathrm{kHz}$ at open circuit potential.

The CPE is defined as

$$
j \cdot Z^{\prime \prime}(\omega)=\frac{1}{Q} j \omega^{-n},
$$

where $Q$ is the CPE constant and has the quality of a susceptance or $Q$-capacitance; $\omega$ is the angular frequency; $0<n<1$ is the factor describing deviation from ideal capacitor [46].

A specific electrochemical element of diffusion, the Warburg element $\left(Z_{w}\right)$ is defined as

$$
\left(Z_{w}\right)=\sigma(1-j) \omega^{-0.5} \text {. }
$$

Here, $\sigma$ denotes the Warburg coefficient. This equation requires that $I Z^{\prime}(\omega) I=I Z^{\prime \prime}(\omega) I$.

\subsection{Electrochemical Monitoring of Antibody Immobilization}

3.2.1. Procedure of Covalent Grafting of the Antibody. Following deposition of the p-aminophenyl (p-AP) film on the gold electrode, the terminal amine was activated by incubation for $60 \mathrm{~min}$ with glutaraldehyde $(25 \%)$ at $\mathrm{pH} \mathrm{4}$, at room temperature [39]. The value of $\mathrm{pH}$ was chosen close to $\mathrm{pKa}$ of aminophenyl group.

After rinsing with PBS, the electrode was incubated for 1 hour in a $0.2 \mathrm{mg} / \mathrm{mL}$ solution of anti-S. aureus antibodies. The amino groups on the antibody molecule enable the covalent bonding with the glutaraldehyde activated amino functions on $\mathrm{Au}$ electrode. The total time necessary for the whole process of preparation of the immunosensor is $3 \mathrm{~h}$.

Finally, after rinsing with PBS, the electrodes were incubated for $20 \mathrm{~min}$ in BSA (1\%) to block the unreacted aldehyde groups. Cyclic voltammetry (CV) and EIS were employed to characterize the p-AP gold electrode (a), p-AP-GA gold electrode (b) and p-AP-GA-Ab gold.
Figure 3(a) shows the CV curves and Figure 3(b) Nyquist plots obtained with these surfaces.

The Faradaic EIS measurements are in good agreement with CV measurements; the current density decreases (Figure 3(a)) and the diameter of the semi-circles of the Nyquist diagrams increases significantly after the different stages of the elaboration of the immunosensor (Figure 3(b)). This indicates that following the observed blocking effect of the p-AP film, a further blocking effect was observed after the binding of glutaraldehyde and the covalent immobilization of the antibody.

3.2.2. Number of Immobilized Antibodies (Binding Sites). In order to calculate the number of binding sites we calculate the antibody surface coverage $\theta_{\mathrm{Ab}}$, using the following equation:

$$
1-\theta_{\mathrm{Ab}}=\frac{R_{\mathrm{CTAP}}}{R_{\mathrm{CTAb}}} .
$$

$R_{\text {CTAb }}$ Charge transfer resistance after antibody immobilization, $R_{\text {CTAP }}$ Charge transfer resistance after grafting of the aminophenyl layer.

$55 \%$ of the surface is found to be covered with antibodies. Considering the surface density for a dense antibody layer determined in [47], the number of immobilized antibodies on the aminophenyl layer, it should be $4.8 \times 10^{12} \mathrm{Ab} / \mathrm{cm}^{2}$.

\subsection{Detection of S. aureus Cells Using Electrochemical} Impedance Spectroscopy. Having developed our sensor, we studied its response towards different concentrations of the S. aureus bacteria. The electrodes were incubated in different 


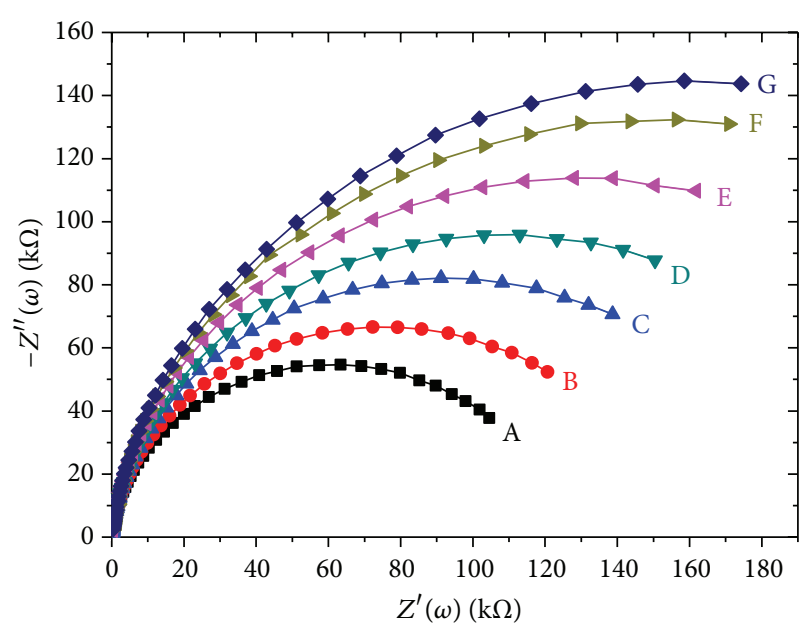

(a)

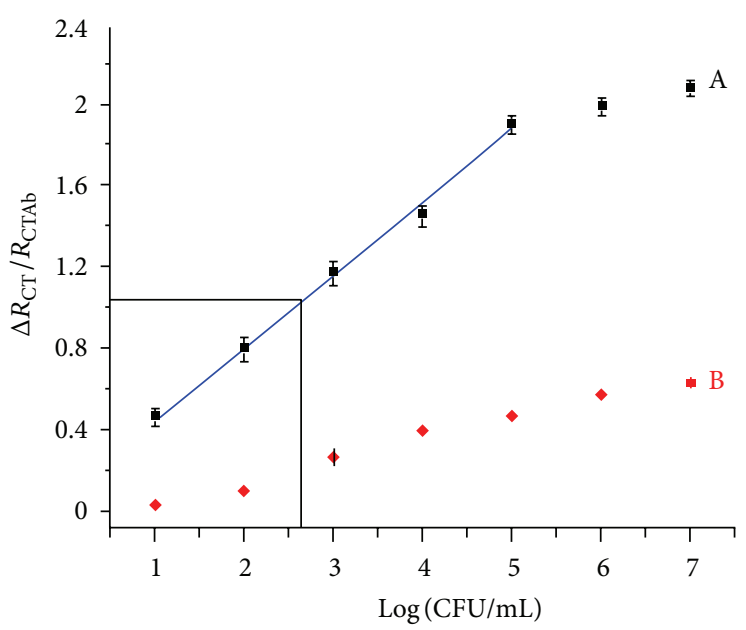

(b)

FIgURE 4: (a) Nyquist plots of impedance spectra obtained for increasing concentrations of S. aureus $(\mathrm{ATCC} 25923)$ in $\mathrm{PBS}$ and $\mathrm{Fe}\left(\mathrm{CN}_{6}\right)^{3-} / /^{4-}$ (A) $10^{1} \mathrm{CFU}$ per $\mathrm{mL}$, (B) $10^{2} \mathrm{CFU}$ per $\mathrm{mL}$, (C) $10^{3} \mathrm{CFU}$ per $\mathrm{mL}$, (D) $10^{4} \mathrm{CFU}$ per $\mathrm{mL}$, (E) $10^{5} \mathrm{CFU}$ per $\mathrm{mL}$, (F) $10^{6} \mathrm{CFU}$ per $\mathrm{mL}$, and (G) $10^{7} \mathrm{CFU}$ per mL. (b) Relative variation of $R_{\mathrm{CT}}\left(\Delta R_{\mathrm{CT}} / R_{\mathrm{CTAb}}=\left(R_{\mathrm{CTBact}}-R_{\mathrm{CTAb}}\right) / R_{\mathrm{CTAb}}\right)$ versus concentration of $S$. aureus (ATCC 25923) in PBS and $\mathrm{Fe}\left(\mathrm{CN}_{6}\right)^{3-} /{ }^{4-}(\mathrm{A})$ incubated on antibody modified aminophenyl-Au electrode and (B) incubated on aminophenyl-Au electrode.

aliquots corresponding to different bacterial concentrations in CFU per mL. Figure 4(a) shows the Nyquist diagrams of the immunosensor obtained after incubation in increasing concentrations of the target bacterium $S$. aureus. The impedance spectra obtained in the presence of different concentrations of bacteria were modeled by the equivalent electrical circuit presented in Figure 2(c).

3.3.1. Surface Coverage by Bacteria. The percentage of surface coverage by bacteria $\theta_{\text {Bact }}$ was determined, according to the following equation:

$$
1-\theta_{\mathrm{Bact}}=\frac{R_{\mathrm{CTAb}}}{R_{\mathrm{CTBact}}} .
$$

$R_{\text {СТАb }}$ Charge transfer resistance after binding antibody, $R_{\text {СTBact }}$ Charge transfer resistance after coverage with bacteria.

Assuming that the surface area of one $S$. aureus bacteriumis $3.14 \mu \mathrm{m}^{2}$ [48], it follows that in presence of a concentration of $10 \mathrm{CFU}$ per $\mathrm{mL}$, the determined surface coverage of the immunosensor is $29 \%$, corresponding to $9 \times 10^{6}$ bacteria per $\mathrm{cm}^{2}$ on the $\mathrm{Ab}$ functionalized gold surface. In the presence of a concentration of $10^{7} \mathrm{CFU}$ per $\mathrm{mL}$, a surface coverage of the immunosensor is $59 \%$, corresponding to $2 \times 10^{7}$ bacteria per $\mathrm{cm}^{2}$ has been determined.

3.3.2. Apparent Equilibrium Dissociation Constant. The reaction flow between immobilized antibody and bacteria is as follows:

$$
\mathrm{Ab}+\mathrm{Bact} \rightleftarrows \mathrm{Ab}-\mathrm{Bact}
$$

Mass action applied to the equilibrium gives

$$
K_{d}=\frac{[\mathrm{Ab}][\mathrm{Bact}]}{[\mathrm{Ab}-\mathrm{Bact}]}
$$

where $K_{d}$ represents the apparent equilibrium dissociation constant; [Ab] and [Bact] respectively are the concentrations of antibody at electrode surface and of bacteria in solution (CFU per $\mathrm{mL}$ ). [Ab-Bact] is the surface concentration of Ab-Bact complex.

If $f(\mathrm{Ab})=[\mathrm{Ab}-\mathrm{Bact}] /[\mathrm{Ab}-\mathrm{Bact}] \max$ and $1-f(\mathrm{Ab})=$ $[\mathrm{Ab}] /[\mathrm{Ab}-\mathrm{Bact}] \max$.

The expression of $K_{d}$ becomes

$$
K_{d}=[\mathrm{Bact}] \frac{(1-f(\mathrm{Ab}))}{f(\mathrm{Ab})} .
$$

The measured relative variation of $R_{\mathrm{CT}}, 9 \Delta R_{\mathrm{CT}}\left(\Delta R_{\mathrm{CT}} /\right.$ $\left.R_{\mathrm{CTAb}}=\left(R_{\mathrm{CTBact}}-R_{\mathrm{CTAb}}\right) / R_{\mathrm{CTAb}}\right)$, after equilibrium with different concentrations of bacteria [Bact], is related to the amount of $\mathrm{Ab}$-Bact complex formed. $\mathrm{G} \Delta R_{\mathrm{CT} \max }$ is the maximum variation obtained corresponding to saturation. It then comes

$$
f(\mathrm{Ab})=\frac{Я \Delta R_{\mathrm{CT}}}{Я \Delta R_{\mathrm{CTmax}}} .
$$

The measured relative variation of $R_{\mathrm{CT}}, \mathrm{Y} \Delta R_{\mathrm{CT}}\left(\Delta R_{\mathrm{CT}} /\right.$ $\left.R_{\mathrm{CTAb}}=\left(R_{\mathrm{CTBact}}-R_{\mathrm{CTAb}}\right) / R_{\mathrm{CTAb}}\right)$, after equilibrium with different concentrations of bacteria [Bact] is presented in Figure 4(b).

$K_{d}$ is equal to [Bact] when $f(\mathrm{Ab})=0.5$. The determined value of $K_{d}$, from Figure $4(\mathrm{~b})$, is $10^{2.6} \mathrm{CFU}$ per $\mathrm{mL}$. 
TABLE 1: A comparison of the analytical characteristics of the immunosensor developed in this work with relevant immunosensors for S. aureus bacteria detection based in the literature.

\begin{tabular}{lccc}
\hline $\begin{array}{l}\text { Type of } \\
\text { transducer }\end{array}$ & $\begin{array}{c}\text { Quantification limit } \\
(\mathrm{CFU} / \mathrm{mL})\end{array}$ & $\begin{array}{c}\text { Dynamic range } \\
(\mathrm{CFU} / \mathrm{mL})\end{array}$ & Reference \\
\hline \multirow{3}{*}{ Impedance } & 10 & $10-10^{6}$ & {$[13]$} \\
& $10^{2}$ & $10^{2}-10^{7}$ & {$[12]$} \\
& 10 & $10-10^{6}$ & {$[14]$} \\
& 10 & $10-10^{7}$ & This work \\
\hline
\end{tabular}

\subsection{Analytical Performance}

3.4.1. Detection Limit, Dynamic Range. The charge transfer resistance increases gradually as the bacteria concentration increases after consecutive incubations from 10 up to $10^{7} \mathrm{CFU}$ per $\mathrm{mL}$. The impedance immunosensor shows a linear relationship between the relative variation of charge transfer $9 \Delta R_{\mathrm{ct}}$ and the decimal logarithmic value of $S$. aureus concentration [Bact] (Figure 4(b)) in a range of 10 to $10^{7} \mathrm{CFU}$ per $\mathrm{mL}$ with a slope of 0.4 and a correlation coefficient of 0.994 , the limit of quantification being $10 \mathrm{CFU}$ per $\mathrm{mL}$.

3.4.2. Reproducibility. The reproducibility of the immunosensor was investigated by repeating the experiments with three different immunosensors prepared in the same conditions. The response for three different immunosensors has an average standard deviation of $20 \%$, which verifies the reproducibility of the system for the detection of $S$. aureus. The drawback is that our immunosensor is not reusable, because we were not able to regenerate our antibodies for other detections.

3.4.3. Specificity. To ensure that the response of our immunosensor was not due to the adsorption of bacteria on the Au surface modified by p-aminophenyl, different electrodes were elaborated in the same conditions, without the antibody incubation step. The results show that there is no significant variation of the relative variation of the charge transfer resistance $9 \Delta R_{\mathrm{ct}}$ of the modified electrode after incubation of the electrode in $S$. aureus solutions (Figure 4(b)).

The specificity of the impedimetric immunosensor system was determined for different bacteria strains at $10^{6} \mathrm{CFU}$ per $\mathrm{mL}$. The relation variation of charge transfer resistance Я $\Delta R_{\mathrm{ct}}$ of the immunosensor for Staphylococcus saprophyticus (ATCC 15305) and Escherichia coli increased less than 0.2, whereas a marked increase by a factor 2 was found after incubation with $S$. aureus cells. Therefore, the specificity of the immunosensor is $10 \%$ for Staphylococcus saprophyticus (ATCC 15305) and Escherichia coli, compared to $100 \%$ for S. aureus. The characteristics of previous relevant immunosensors for S. aureus detection in terms of the limit of detection (LOQ) and of the dynamic range are given in Table 1 . In this work, the LOQ obtained for the developed immunosensor is the lowest value and the largest dynamic range is obtained.

\section{Conclusion}

An impedance-based immunosensor for the detection of $S$. aureus has been developed. Electrochemical grafting of the gold electrode surface by $\mathrm{p}$-aminophenyl (p-AP) was demonstrated as a suitable, simple, and versatile platform for antibody immobilization, giving stable and robust biomolecular layers. It allows rapid, inexpensive, sensitive, and selective detection of these bacteria. This method permits antibodies to be spatially addressed on a single gold chip in a microarray and then allows simultaneous detection of different bacteria. Further studies are in progress for the use on real samples.

\section{Acknowledgments}

The authors would like to thank EGIDE for its support through UTIQUE Program no. 09G 1128 and through PHC Maghreb no. 12 MAG 088. Amina Chrouda is grateful to the Tunisian Ministry of Higher Education and Technology for the "Mobility Grant".

\section{References}

[1] B. Kouidhi, T. Zmantar, H. Hentati, and A. Bakhrouf, "Cell surface hydrophobicity, biofilm formation, adhesives properties and molecular detection of adhesins genes in Staphylococcus aureus associated to dental caries," Microbial Pathogenesis, vol. 49, no. 1-2, pp. 14-22, 2010.

[2] R. Ananthanarayan and C. K. J. Panikaran, "Diagnostic value of mannitol for sugar fermentation in S. aureus," in Textbook of Microbiology, S. Kumar, Ed., vol. 6, pp. 178-186, 2001.

[3] I. Hein, A. Lehner, P. Rieck, K. Klein, E. Brandl, and M. Wagner, "Comparison of different approaches to quantify Staphylococcus aureus cells by real-time quantitative PCR and application of this technique for examination of cheese," Applied and Environmental Microbiology, vol. 67, no. 7, pp. 3122-3126, 2001.

[4] R. W. Bennett, "Staphylococcal enterotoxin and its rapid identification in foods by enzyme-linked immunosorbent assay-based methodology," Journal of Food Protection, vol. 68, no. 6, pp. 1264-1270, 2005.

[5] E. Leoni, G. D. Luca, P. P. Legnani, R. Sacchetti, S. Stampi, and F. Zanetti, "Legionella waterline colonization: detection of Legionella species in domestic, hotel and hospital hot water systems," Journal of Applied Microbiology, vol. 98, no. 2, pp. 373379, 2005.

[6] M. Nayak, A. Kotian, S. Marathe, and D. Chakravortty, "Detection of microorganisms using biosensors-A smarter way towards detection techniques," Biosensors and Bioelectronics, vol. 25, no. 4, pp. 661-667, 2009.

[7] E. Tully, S. P. Higson, and R. O'Kennedy, "The development of a "labeless" immunosensor for the detection of Listeria monocytogenes cell surface protein, Internalin B," Biosensors and Bioelectronics, vol. 23, no. 6, pp. 906-912, 2008.

[8] D. Li, Y. Feng, L. Zhou et al., "Label-free capacitive immunosensor based on quartz crystal Au electrode for rapid and sensitive detection of Escherichia coli O157:H7," Analytica Chimica Acta, vol. 687, no. 1, pp. 89-96, 2011.

[9] A. Subramanian, J. Irudayaraj, and T. Ryan, "A mixed selfassembled monolayer-based surface plasmon immunosensor for detection of E. coli O157:H7," Biosensors and Bioelectronics, vol. 21, no. 7, pp. 998-1006, 2006. 
[10] O. Laczka, E. Baldrich, F. X. Muñoz, and F. J. Del Campo, "Detection of Escherichia coli and Salmonella typhimurium using interdigitated microelectrode capacitive immunosensors: the importance of transducer geometry," Analytical Chemistry, vol. 80, no. 19, pp. 7239-7247, 2008.

[11] F. Salam and I. E. Tothill, "Detection of Salmonella typhimurium using an electrochemical immunosensor," Biosensors and Bioelectronics, vol. 24, no. 8, pp. 2630-2636, 2009.

[12] V. Escamilla-Gómez, S. Campuzano, M. Pedrero, and J. M. Pingarrón, "Electrochemical immunosensor designs for the determination of Staphylococcus aureus using 3,3-dithiodipropionic acid di(N-succinimidyl ester)-modified gold electrodes," Talanta, vol. 77, no. 2, pp. 876-881, 2008.

[13] F. Tan, P. H. M. Leung, Z.-B. Liu et al., "A PDMS microfluidic impedance immunosensor for E. coli O157:H7 and Staphylococcus aureus detection via antibody-immobilized nanoporous membrane," Sensors and Actuators B, vol. 159, no. 1, pp. 328-335, 2011.

[14] M. Braiek, K. Bekir Rokbani, A. Chrouda et al., "An electrochemical immunosensor for detection of Staphylococcus aureus bacteria based on immobilization of antibodies on selfassembled monolayers-functionalized gold electrode," Biosensors, vol. 2, no. 4, pp. 417-426, 2012.

[15] M. Delamar, R. Hitmi, J. Pinson, and J. M. Savéant, "Covalent modification of carbon surfaces by grafting of functionalized aryl radicals produced from electrochemical reduction of diazonium salts," Journal of the American Chemical Society, vol. 114, no. 14 , pp. 5883-5884, 1992.

[16] C. Saby, B. Ortiz, G. Y. Champagne, and D. Bélanger, "Electrochemical modification of glassy carbon electrode using aromatic diazonium salts, blocking effect of 4-nitrophenyl and 4-carboxyphenyl groups," Langmuir, vol. 13, no. 25, pp. 68056813, 1997.

[17] J. Lyskawa and D. Bélanger, "Direct modification of a gold electrode with aminophenyl groups by electrochemical reduction of in situ generated aminophenyl monodiazonium cations," Chemistry of Materials, vol. 18, no. 20, pp. 4755-4763, 2006.

[18] G. Z. Liu, T. Böcking, and J. J. Gooding, "Diazonium salts: stable monolayers on gold electrodes for sensing applications," Journal of Electroanalytical Chemistry, vol. 600, no. 2, pp. 335-344, 2007.

[19] A. Adenier, M.-C. Bernard, M. M. Chehimi et al., "Covalent modification of iron surfaces by electrochemical reduction of aryldiazonium salts," Journal of the American Chemical Society, vol. 123, no. 19, pp. 4541-4549, 2001.

[20] A. Chaussé, M. M. Chehimi, N. Karsi, J. Pinson, F. Podvorica, and C. Vautrin-Ul, "The electrochemical reduction of diazonium salts on iron electrodes. The formation of covalently bonded organic layers and their effect on corrosion," Chemistry of Materials, vol. 14, no. 1, pp. 392-400, 2002.

[21] J. J. Gooding, "Advances in interfacial design for electrochemical biosensors and sensors: aryl diazonium salts for modifying carbon and metal electrodes," Electroanalysis, vol. 20, no. 6, pp. 573-582, 2008.

[22] R. Polsky, J. C. Harper, D. R. Wheeler, and S. M. Brozik, "Multifunctional electrode arrays: towards a universal detection platform," Electroanalysis, vol. 20, no. 6, pp. 671-679, 2008.

[23] A. Hayat, L. Barthelmebs, A. Sassolas, and J.-L. Marty, "An electrochemical immunosensor based on covalent immobilization of okadaic acid onto screen printed carbon electrode via diazotization-coupling reaction," Talanta, vol. 85, no. 1, pp. 513518, 2011.
[24] C. M. A. Brett, S. Kresak, T. Hianik, and A. M. O. Brett, "Studies on self-assembled alkanethiol monolayers formed at applied potential on polyerystalline gold electrodes," Electroanalysis, vol. 15, no. 5-6, pp. 557-565, 2003.

[25] P. Allongue, M. Delamar, B. Desbat et al., "Covalent modification of carbon surfaces by aryl radicals generated from the electrochemical reduction of diazonium salts," Journal of the American Chemical Society, vol. 119, no. 1, pp. 201-207, 1997.

[26] G. Liu, E. Luais, and J. J. Gooding, "The fabrication of stable gold nanoparticle-modified interfaces for electrochemistry," Langmuir, vol. 27, no. 7, pp. 4176-4183, 2011.

[27] B. P. Corgier, A. Laurent, P. Perriat, L. J. Blum, and C. A. Marquette, "A versatile method for direct and covalent immobilization of DNA and proteins on biochips," Angewandte Chemie International Edition, vol. 46, no. 22, pp. 4108-4110, 2007.

[28] A.-E. Radi, X. Muñoz-Berbel, M. Cortina-Puig, and J.-L. Marty, "A third-generation hydrogen peroxide biosensor based on horseradish peroxidase covalently immobilized on electrografted organic film on screen-printed carbon electrode," Electroanalysis, vol. 21, no. 14, pp. 1624-1629, 2009.

[29] J. L. Bahr and J. M. Tour, "Highly functionalized carbon nanotubes using in situ generated diazonium compounds," Chemistry of Materials, vol. 13, no. 11, pp. 3823-3824, 2001.

[30] O. A. de Fuentes, T. Ferri, M. Frasconi, V. Paolini, and R. Santucci, "Highly-ordered covalent anchoring of carbon nanotubes on electrode surfaces by diazonium salt reactions," Angewandte Chemie, vol. 50, no. 15, pp. 3457-3461, 2011.

[31] B. Chen, A. K. Flatt, H. Jian, J. L. Hudson, and J. M. Tour, "Molecular grafting to silicon surfaces in air using organic triazenes as stable diazonium sources and HF as a constant hydride-passivation source," Chemistry of Materials, vol. 17, no. 19, pp. 4832-4836, 2005.

[32] A. J. Downard and M. J. Prince, "A simple approach to patterned protein immobilization on silicon via electrografting from diazonium salt solutions," Langmuir, vol. 17, pp. 5581-5586, 2001.

[33] A.-E. Radi, X. Muñoz-Berbel, V. Lates, and J.-L. Marty, "Labelfree impedimetric immunosensor for sensitive detection of ochratoxin A," Biosensors and Bioelectronics, vol. 24, no. 7, pp. 1888-1892, 2009.

[34] S. Mahouche-Chergui, S. Gam-Derouich, C. Mangeney, and M. M. Chehimi, "Aryl diazonium salts: a new class of coupling agents for bonding polymers, biomacromolecules and nanoparticles to surfaces," Chemical Society Reviews, vol. 40, no. 7, pp. 4143-4166, 2011.

[35] D. Bélanger and J. Pinson, "Electrografting: a powerful method for surface modification," Chemical Society Reviews, vol. 40, no. 7, pp. 3995-4048, 2011.

[36] A. Adenier, E. Cabet-Deliry, A. Chaussé et al., "Grafting of aryl groups on carbon or metallic surfaces without electrochemical induction," Chemistry of Materials, vol. 17, pp. 491-501, 2005.

[37] A. Ramanavicius, A. Finkelsteinas, H. Cesiulis, and A. Ramanaviciene, "Electrochemical impedance spectroscopy of polypyrrole based electrochemical immunosensor," Bioelectrochemistry, vol. 79, no. 1, pp. 11-16, 2010.

[38] P. Geng, X. Zhang, W. Meng et al., "Self-assembled monolayersbased immunosensor for detection of Escherichia coli using electrochemical impedance spectroscopy," Electrochimica Acta, vol. 53, no. 14, pp. 4663-4668, 2008.

[39] A.-E. Radi, X. Muñoz-Berbel, M. Cortina-Puig, and J.-L. Marty, "An electrochemical immunosensor for ochratoxin A based on immobilization of antibodies on diazonium-functionalized 
gold electrode," Electrochimica Acta, vol. 54, no. 8, pp. 21802184, 2009.

[40] A. Mesnage, X. Lefevre, P. Jegou, G. Deniau, and S. Palacin, "Spontaneous grafting of diazonium salts: chemical mechanism on metallic surfaces," Langmuir, vol. 28, pp. 11767-11778, 2012.

[41] P. A. Brooksby and A. J. Downard, "Electrochemical and atomic force microscopy study of carbon surface modification via diazonium reduction in aqueous and acetonitrile solutions," Langmuir, vol. 20, no. 12, pp. 5038-5045, 2004.

[42] P. A. Brooksby and A. J. Downard, "Multilayer nitroazobenzene films covalently attached to carbon. An AFM and electrochemical study," Journal of Physical Chemistry B, vol. 109, no. 18, pp. 8791-8798, 2005.

[43] M. Kullapere, M. Marandi, L. Matisen et al., "Blocking properties of gold electrodes modified with 4-nitrophenyl and 4decylphenyl groups," Journal of Solid State Electrochemistry, vol. 16, no. 2, pp. 569-578, 2012.

[44] A. L. Gui, G. Liu, M. Chockalingam et al., "A comparative study of electrochemical reduction of 4-nitrophenyl covalently grafted on gold and carbon," Electroanalysis, vol. 22, no. 16, pp. 1824-1830, 2010.

[45] A. Chira, O.-I. Covaci, and G. L. Radu, "A comparative study of gold electrodes modification methods with aromatic compounds based on diazonium and thiol chemistry," UPB Scientific Bulletin B, vol. 74, no. 1, pp. 183-192, 2012.

[46] J. Bisquert, G. Garcia-Belmonte, P. Bueno, E. Longo, and L. O. S. Bulhões, "Impedance of constant phase element (CPE)blocked diffusion in film electrodes," Journal of Electroanalytical Chemistry, vol. 452, no. 2, pp. 229-234, 1998.

[47] J. T. La Belle, K. Bhavsar, A. Fairchild et al., "A cytokine immunosensor for multiple sclerosis detection based upon label-free electrochemical impedance spectroscopy," Biosensors and Bioelectronics, vol. 23, no. 3, pp. 428-431, 2007.

[48] L. G. Harris, S. J. Foster, R. G. Richards, P. Lambert, D. Stickler, and A. Eley, "An introduction to Staphylococcus aureus, and techniques for identifyingand quantifying $S$. aureus adhesins in relation to adhesion to biomaterials: review," European Cells \& Materials, vol. 4, pp. 39-60, 2002. 

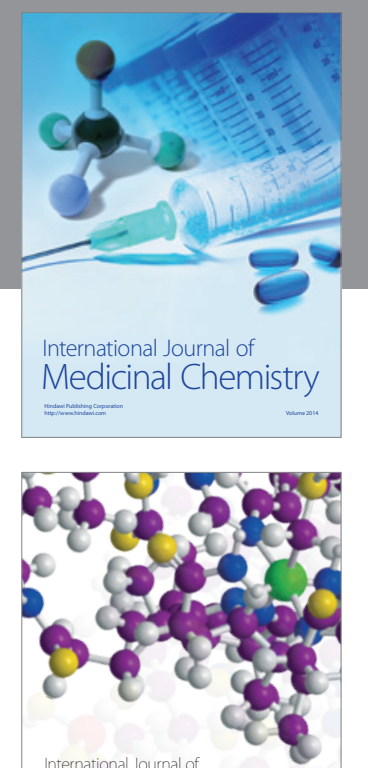

\section{Carbohydrate} Chemistry

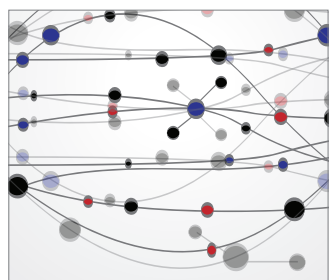

The Scientific World Journal
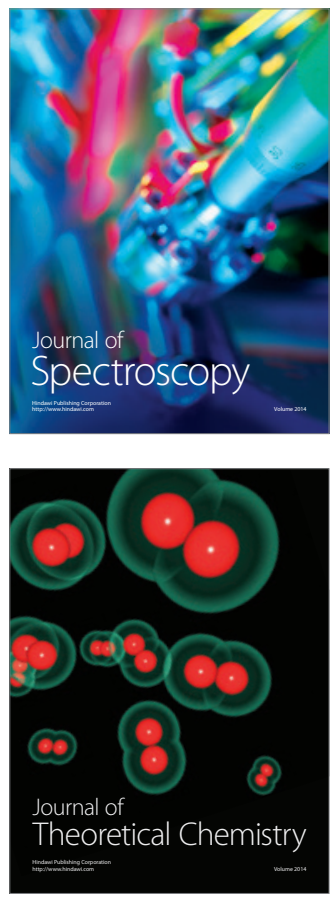
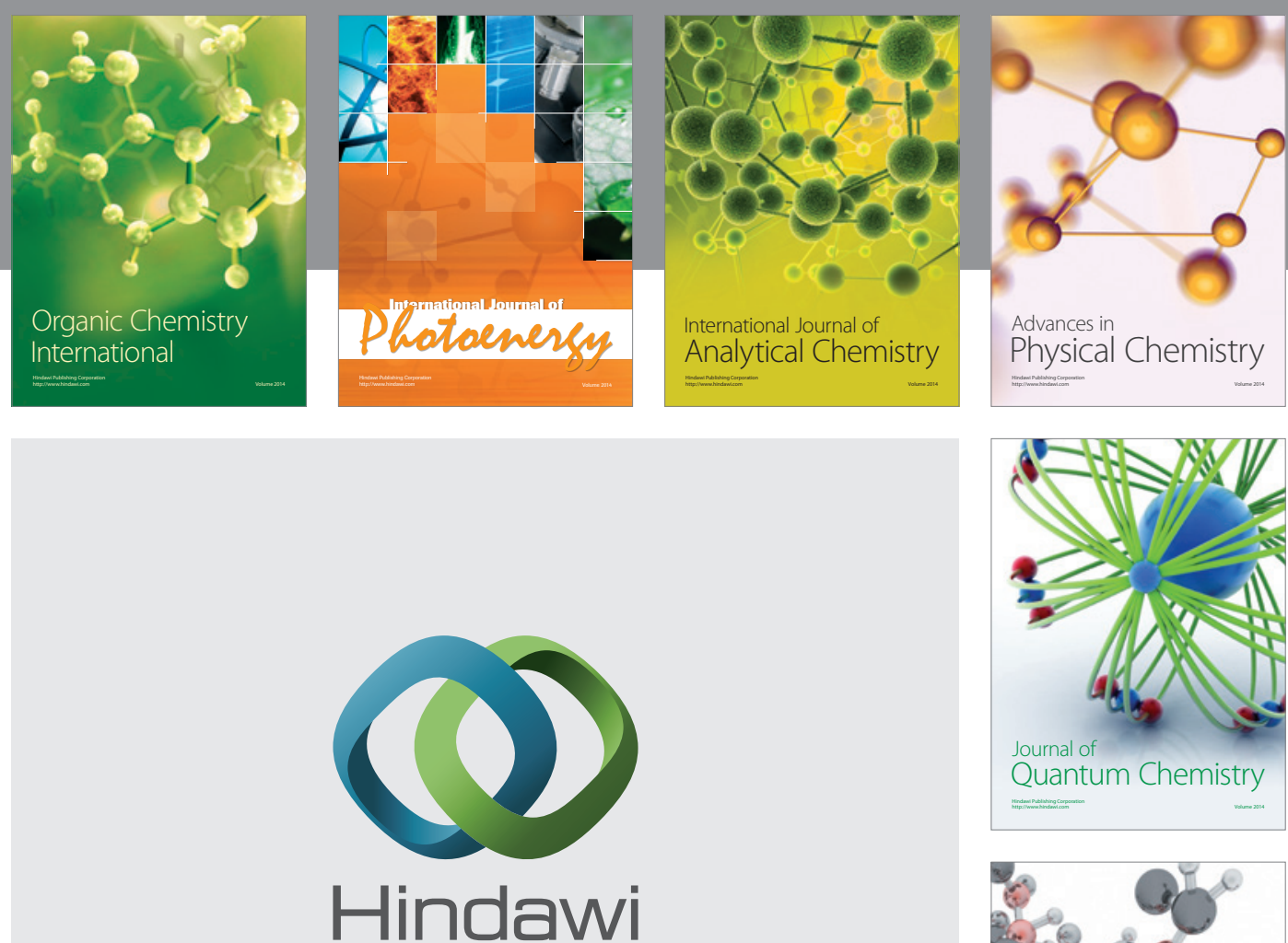

Submit your manuscripts at

http://www.hindawi.com

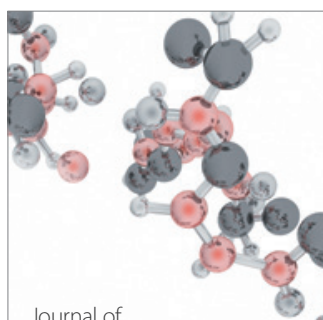

Analytical Methods

in Chemistry

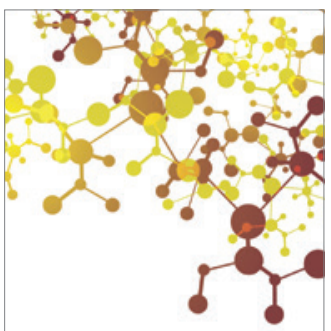

Journal of

Applied Chemistry

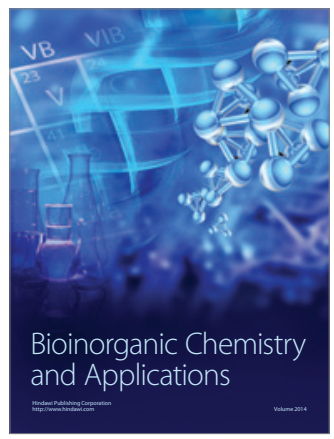

Inorganic Chemistry
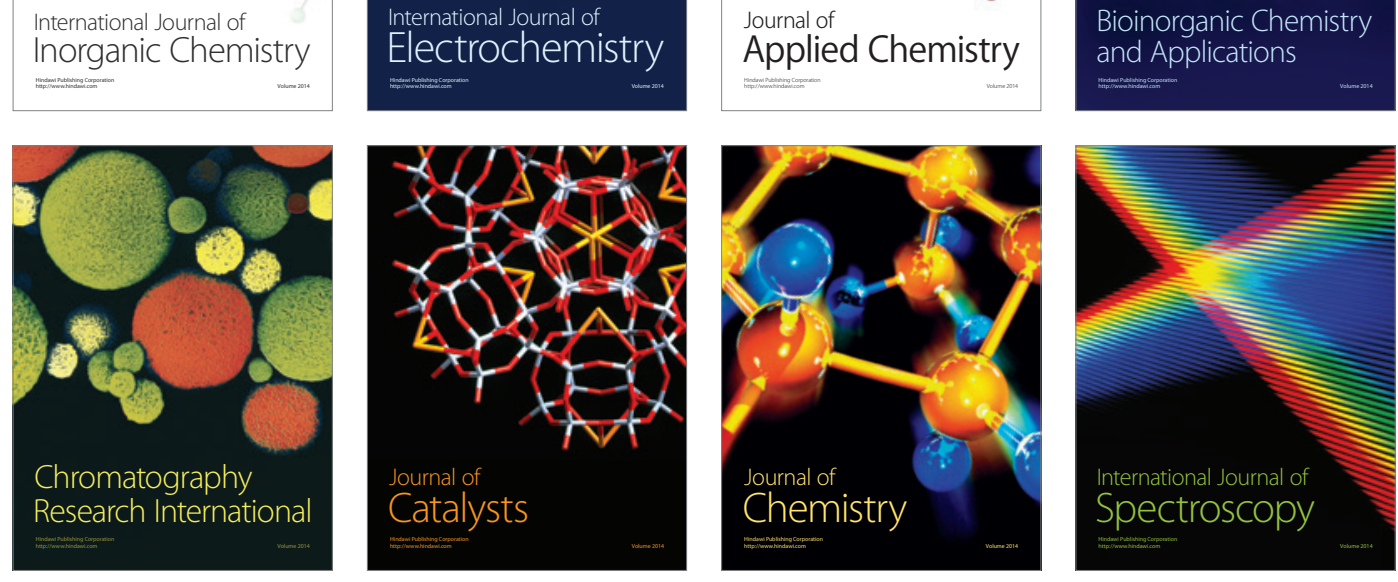